\title{
More than simply microbial growth curves
}

\author{
Ji-Dong Gu \\ School of Biological Sciences, The University of Hong Kong, Pokfulam Road, Hong Kong SAR, People’s Republic of China
}

\begin{abstract}
Bacterial growth is a very important piece of information in a wide range of investigation and, in most of the time the data are simply shown directly without any further processing. In a single factor investigation without comparative information to be extracted, this simple approach can be used together with other data to form a comprehensive set of results. When comparison is involved, such direct showing of bacterial growth curves without processing cannot warrant a meaningful comparison thoroughly and further processing of data is necessary. In addition, there is little, if any, quantitative data for the comparison from the display of growth curves and description of a number of curves is not a simple task, especially in a meaningful way for assimilation of the data to readers. With this in mind, I would like to remind of those who plan to show such data as growth curves for their potential publication to carry this further to generate comparative results for a much meaningful interpretation by modeling and calculation from the raw growth data over time of incubation. By calculating with existing equations, the lag phase, growth rate and the biomass can be derived from a series of growth curves for a more effective and meaningful analysis. This approach is not new, but remembrance of such available tool is more important so that research data are shown professionally and also scientifically for meaning presentation and effective assimilation.
\end{abstract}

Keywords: biomass, bacterial growth curves, bacterial physiology, maximum growth rate, maximum biomass yield

*Correspondence to: Ji-Dong Gu, School of Biological Sciences, The University of Hong Kong, Pokfulam Road, Hong Kong SAR, People’s Republic of China; Email: jdgu@hku.hk

Received: November 10, 2016; Accepted: November 24, 2016; Published Online: November 30, 2016

Citation: Gu J-D, 2016, More than simply microbial growth curves. Applied Environmental Biotechnology, vol.1(2): 6365. http://dx.doi.org/10.26789/AEB.2016.02.007.

\section{Introduction}

$\mathrm{B}$ acterial growth and biomass can be easily assayed in a number of ways, including direct cell counting and colony-forming units on agar plates, and indirect protein assay or determination of the optical density (OD) of bacterial culture spectrophotometrically to derive information on cellular physiology and performance in the form of yield. Among all these methods, OD reading is the most convenient and easiest to implement in research laboratories and also industrial settings because of convenience and efficiency, and have been shown and reported most widely in published papers ${ }^{[1-3]}$. When dealing with a single bacterial isolate or strain under investigation, OD values can be adequate to provide the bacterial physiological function and biochemical activity under the specific conditions of investigation. However, this type of approach is not so effective when the concentration effects of substrates and toxicants are the central theme of the study in the experimental design. In addition, under such situations, a large number of bacterial growth curves accumulated from the different concentration treatments and conditions are not easily presented to describe in the results and discussion efficiently in any potential paper. With this in mind and also from my previous and current experiences in handling manuscripts submitted to different journals, I would like to remind authors and graduate students on the data processing possibilities to derive meaningful microbiological parameters important and essential to bacterial growth under the treatments or

More than simply microbial growth curves. (C) $2016 \mathrm{Ji}$-Dong Gu. This is an Open Access article distributed under the terms of the Creative Commons Attribution-NonCommercial 4.0 International License (http://creativecommons.org/licenses/by- nc/4.0/), permitting all non-commercial use, distribution, and reproduction in any medium, provided the original work is properly cited. 
conditions of the investigation to advance the investigation objectives $^{[4-8]}$.

\section{Bacteria Growth Curve}

Bacterial growth curves can be used effectively or less meaningfully depending on the situation of the experiments and also the ways to present such data. A typical bacterial growth curve has the lag $(\lambda)$, exponential growth $(\mu)$, stationary and declining phases ${ }^{[9]}$. As a complementary part of the microbial transformation, degradation and growth, OD values can go together with the depletion of substrate concentration nicely to form a coherent and convincing set of results for the degradation taking place in the flasks and this approach is mostly implemented with pure culture or isolates $s^{[1,2,4-8]}$. Under other conditions evaluating a set of variables especially at a range of concentrations for their effects on bacterial growth or degradation or ecotoxicology, the large number of bacterial growth curves obtained by showing OD values versus time of incubation not only occupy too much of printing space but also create complicated situations, which is difficult for the eyes and also for the brain to process the data because the shapes of the curves and the specific information from each of them cannot be simultaneously assimilated and converted to meaningful summarized information by our brain quickly and remembered immediately. Under other conditions, growth of bacteria can also be assessed by monitoring the bacterial growth in flask through collecting the OD values, such results, after further processing to make a meaningful summary for effective presentation, can be highly informative on the bacterial growth competitiveness under the various conditions imposed to Vibrio species as an example ${ }^{[10,11]}$. Because of this, the existing mathematical approach can be used to process this collection of data sets to selective bacterial growth indicator values, e.g., specific growth rate, maximum biomass yield and lag phase to form the basis for a meaningful comparison, evaluation and judgment on the research objectives from the data set.

The model to describe the bacterial growth curve can be based on the known Gompertz model (Equation 1), which is the most suitable to fit the growth of microorganisms, e.g., Lactobacillus plantarum and easy to use ${ }^{[9]}$.

$$
X=A \exp \left\{-\exp \left[\frac{\mu_{m} e}{A}(\lambda-t)+1\right]\right\}
$$

When degradation of an organic substrate or pollutant is the theme of investigation, the Richards function in a similar way as mentioned above, can be rearranged $^{[7,8]}$ as:

$$
\begin{aligned}
& S= \\
& S_{0}\left\{1-\left\{1+(m-1) \cdot e^{m} \cdot \exp \left[\frac{\mu_{m}}{S_{0}} \cdot m^{\frac{m}{m-1}} \cdot(\lambda-t)\right]\right\}^{\frac{1}{1-m}}\right\}
\end{aligned}
$$

These examples above illustrate one crucially important fact on that simple data have fundamentally significant meaning when treated and presented properly. Small research projects can also generate huge impact if the power of the brain is fully activated to execute the whole process from planning, conducting to integrating and summarizing the data obtained. I would like to use this opportunity to communicate with young investigators to assimilate the basic and essential knowledge so that their judgment can be critical and selective in their scientific and research careers to contribute to the new innovation and knowledge based on meticulously designed experiments and the reliable scientific data of their work ${ }^{[12]}$.

\section{Conclusion}

Scientific investigation is a constant effort driven by curiosity and original idea of exceptional talent and comprehension. In addition to new breakthroughs, routine methods are still used to derive extended information for establishment of a concept and hypothesis substantially. For those of us who use routine methods, small innovation can also be realized through incorporation of methods by others ${ }^{[9]}$, so that our research data are not only professionally presented, but also more concentrated and meaningful. It is the purpose of my initiative here to use this commentary to show a specific case from my personal experiences to provide alternative approaches for young scientists and especially graduate students to consider their research data and results so that they benefit from those who had experienced them before.

\section{Conflict of Interest and Funding}

There is no conflict of interest in this publication. Research in my laboratory has been supported by Hong Kong SAR Government and RGC GRF grants.

\section{References}

1. Gu J-D, and Pan L, 2006, Comparison of growth charac- 
teristics of three bacteria involved in degrading rubber. Journal of Polymers and the Environment, vol.14: 273-279. http://dx.doi.org/10.1007/s10924-006-0016-5.

2. Yip C Y K and Gu J-D, 2016, A novel bacterium involved in the degradation of 2-methylindole isolated from sediment of Inner Deep Bay of Hong Kong. Applied Environmental Biotechnology, vol.1(1): 52-63. http://dx.doi.org/10.18063/AEB.2016.01.008.

3. Mitchell R and Gu J-D, 2010, Environmental Microbiology ( $2^{\text {nd }}$ ed.). John Wiley, New York.

4. Li J, Gu J-D and Pan L, 2005, Transformation of dimethyl phthalate, dimethyl isophthalate and dimethyl terephthalate by Rhodococcus rubber Sa and modeling the processes using the modified Gompertz model. International Biodeterioration \& Biodegradation, vol.55: 223-232. http://dx.doi.org/10.1016/j.ibiod.2004.12.003.

5. Wang Y, Fan Y and Gu J-D, 2003, Microbial degradation of the endocrine-disrupting chemicals phthalic acid and dimethyl phthalate ester under aerobic conditions. Bulletin of Environmental Contamination and Toxicology, vol. 71(4): 810-818. http://dx.doi.org/10.1007/s00128-003-0207-x.

6. Wang Y, Fan Y and Gu J-D, 2003, Aerobic degradation of phthalic acid by Comamonas acidovoran fy-1 and dimethyl phthalate ester by two reconstituted consortia from sewage sludge at high concentrations. World Journal of Microbiology \& Biotechnology, vol.19(8): 811-815. http://dx.doi.org/10.1023/A:1026021424385.
7. Fan Y, Wang Y, Qian P, et al. 2004, Optimization of phthalic acid batch biodegradation and the use of modified Richards model for modeling degradation. International Biodeterioration \& Biodegradation, vol.53(1): 57-63. http://dx.doi.org/10.1016/j.ibiod.2003.10.001.

8. Wang, Y, Fan Y and Gu J-D, 2004, Dimethyl phthalate ester degradation by two planktonic and immobilized bacterial consortia. International Biodeterioration \& Biodegradation, vol.53(2): 93-101. http://dx.doi.org/10.1016/j.ibiod.2003.10.005.

9. Zwietering $\mathrm{M} \mathrm{H}$, Jongenburger, I, Rombouts $\mathrm{F}$ M, et al. 1990, Modeling of the bacterial growth curve. Applied and Environmental Microbiology, vol.56(6), 1875-1881.

10. Wang Y, Leung P C, Qian P, et al. 2004, Effects of UV, $\mathrm{H}_{2} \mathrm{O}_{2}$ and $\mathrm{Fe}^{3+}$ on the growth of four environmental isolates of Aeromonas and Vibrio species isolated from a mangrove environment. Microbes and Environments, vol.19(2): 163-171. http://dx.doi.org/10.1264/jsme2.19.163.

11. Wang Y, and Gu J-D, 2005, Influence of temperature, salinity and $\mathrm{pH}$ on the growth of environmental isolates of Aeromonas and Vibrio species isolated from Mai Po and the Inner Deep Bay Nature Reserve Ramsar site of Hong Kong. Journal of Basic Microbiology, vol.45(1): 83-93. http://dx.doi.org/10.1002/jobm.200410446.

12. Gu J-D, 2015, A Foreword from the Editor. Applied Environmental Biotechnology, vol.1(1): 1-2. http://dx.doi.org/10.18063/AEB.2016.01.001. 